\title{
Iconclass: Clasificación Iconográfica para la ordenación, resumen e indización de la documentación icónica
}

\author{
Luis Miguel Moreno Fernández \\ Manuel Caparrós Perales \\ Universidad de Murcia (España)
}

\subsection{Resumen}

Se estudia el sistema de clasificación iconográfica Iconclass. Se analiza su utilización en bases de datos iconográficas, así como su estructura y funcionamiento, comparándolos con los lenguajes de indización más utilizados. Iconclass desempeña las funciones de una clasificación jerárquica, pero además permite indizar los documentos y describirlos por medio de un resumen proporcionado por la rúbrica que acompaña a sus códigos.

Palabras clave: Clasificación Iconográfica (ICONCLASS). Lenguajes controlados. Tesauros. Sistemas de clasificación. Documentos icónicos.

\subsection{Abstract}

The Iconographic Classification System (ICONCLASS) is studied. Its use in different databases, structure and use is analyzed, comparing them with the features offered by more traditional and well-known indexing languages. Iconclass works as a classification scheme, but also allows the indexing and abstracting of images by the headings of the assigned alphanumeric codes.

Keywords: Iconographic Classification (ICONLASS). Controlled languages. Indexing. Thesauri. Classification Systems. Iconographic documents.

\section{Génesis y naturaleza de Iconclass}

Desde hace años Iconclass viene tratando de normalizar el acceso a los contenidos de los documentos icónicos. Este objetivo se revela de capital importancia en entornos informáticos que manejan vastos archivos electrónicos de imágenes, porque el incremento de su rendimiento en las búsquedas por materias requiere un proceso previo en la descripción y clasificación de los contenidos informativos de ese tipo de materiales coherente y sistemático, rasgos que sólo un vocabulario controlado puede proporcionar. Su creador fue el profesor holandés Henri Van de Scire. $10: 1$ (en.-jun. 2004) 51-64. 
Waal (1910-1972), pero el lenguaje documental en su forma completa vio la luz tras su fallecimiento, gracias a que un nutrido grupo de investigadores prosiguió su labor. Fruto de un trabajo de cuarenta años fueron los diecisiete volúmenes editados entre 1973 y 1985 (Waal, 1973-1985).

\section{Principios y características de Iconclass}

En este apartado vamos a tratar de dilucidar qué es Iconclass en el contexto de los lenguajes documentales, para que la comparación de sus características principales nos arroje luz acerca de las semejanzas y diferencias que existen entre ellos y nos ilustre mejor acerca de su naturaleza y de sus funciones documentales. Esto es necesario porque las referencias y definiciones que nos han facilitado los propios creadores de este sistema iconográfico son muy poco precisas a ese respecto, tal vez porque no provienen del ámbito de la documentación. Para proceder a una disección eficaz y clarificadora de esta clasificación iconográfica hemos procedido a tabular los rasgos básicos de los lenguajes documentales atendiendo a sus principios, estructura y utilización, y a compararlos con los que ofrece Iconclass en las mismas dimensiones.

El sistema Iconclass se desarrolla en un contexto en el que la Historia del Arte se concebía como una parte genuina de la más amplia historia cultural y donde la recuperación de información se entiende basada en la organización sistemática. Es por eso por lo que, en la propia web oficial, se define aquél como "un sistema de clasificación específico por materias; es una colección ordenada jerárquicamente de definiciones de objetos, personas, acontecimientos e ideas abstractas que pueden ser materia de una imagen" (Iconclass, 2003). Aunque esta definición es poco precisa y parcial, en la medida que no refleja todas las posibilidades del lenguaje documental, sí que permite hacernos a la idea de que no estamos ante un lenguaje documental muy corriente en los centros de documentación. En realidad, desde la perspectiva del "uso" que de él puede hacerse, presenta unas peculiaridades que le hacen conjugar las características de los lenguajes documentales clasificatorios y de los tesauros, como tendremos la oportunidad de apreciar conforme nos adentremos en su conocimiento. Incluso llega a más, porque esas "definiciones" - rúbricas en los lenguajes clasificatorios - son susceptibles de emplearse como breves resúmenes indicativos de las imágenes. Si aceptamos esa premisa, inferimos que Iconclass es un lenguaje controlado, igual que aquéllos, a pesar de que haya quienes lo nieguen expresamente. El control del vocabulario viene dado por la elección del vocabulario iconográfico escogido de manera precisa entre las obras de los autores incluidos en la bibliografía referida al final de la obra. Esto hace que haya sido esencial para la elaboración del lenguaje el análisis sistemático de todas las obras de iconografía escritas sobre los más

Scire. $10: 1$ (en.-jun. 2004) 51-64. 
diversos temas artísticos. Tras el estudio de las mismas se formulan definiciones de conceptos abstractos, elementos o partes específicas referidos al Arte.

Iconclass constituye una larga serie de definiciones formuladas "a priori", susceptibles de emplearse para describir los "contenidos" de los materiales visuales. Son apriorísticas porque funcionan como si se tratasen de etiquetas realizadas a partir de conceptos abstractos, elementos o partes específicas del Arte. Iconclass se asemeja a un tesauro que presenta el conocimiento iconográfico ordenado jerárquicamente, pero, a diferencia de este lenguaje, incluye 24.000 definiciones de objetos, personas, eventos, situaciones e ideas abstractas. Por lo tanto, es un lenguaje documental muy potente para la descripción característica, la clasificación y el acceso a los documentos visuales, cuyas características se recogen en la tabla I.

\begin{tabular}{|c|c|c|c|c|}
\hline & 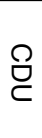 & 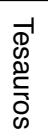 & $\stackrel{\rho}{\circ}$ & $\begin{array}{l}\bar{\delta} \\
\frac{0}{\partial} \\
\frac{\rho}{0} \\
\text { ळ }\end{array}$ \\
\hline Lenguaje controlado & + & + & + & + \\
\hline Localización física del documento & + & - & + & + \\
\hline Lenguaje especializado & - & + & - & + \\
\hline Evolución "acelerada" & - & + & - & + \\
\hline Codificación alfanumérica de la información & - & - & - & + \\
\hline Indización precoordinada & + & - & + & + \\
\hline Representación sintética del documento & + & - & + & + \\
\hline
\end{tabular}

Tabla I. Rasgos distintivos de Iconclass en el contexto de los lenguajes documentales

Tales definiciones son susceptibles de equipararse a las "rúbricas" que acompañan a los números de la Clasificación Decimal Universal (CDU), y, al igual que sucede en ella, constituyen "etiquetas" representadas por un código alfanumérico, que se asignan a las obras que queremos describir. Las notaciones alfanuméricas constituyen el elemento básico para codificar la información que proporciona el sistema; y se utilizan igual que los guarismos de la CDU o los descriptores del tesauro. Esto propicia que Iconclass sea un amplio lenguaje independiente y libre de los ambages propios del lenguaje natural - sus definiciones son el fruto del conocimiento iconográfico de gran número de estudiosos - , así como de gran alcance - "universal", cabría decir, si seguimos las pautas empleadas para describir los lenguajes documentales al uso en documentación-.

Scire. $10: 1$ (en.-jun. 2004) 51-64. 
Sin embargo, conviene matizar unas diferencias en este terreno respecto de otros lenguajes documentales, tal y como se observan en la tabla I. Mientras que en la Clasificación Decimal de Dewey (CDD) y en la CDU la codificación de la información es numérica en sentido estricto - o, en el polo opuesto, en los tesauros se efectúa por medio de descriptores-, en Iconclass aparecen conjugados letras y guarismos. Creemos que la codificación alfanumérica se creó, precisamente, para evitar la complejidad y eventuales confusiones que implica la creación de dígitos demasiado largos separados por signos de puntuación. Claro está que esto también puede representar una limitación dentro del desarrollo jerárquico de cada materia, ya que una materia no podrá tener una subdivisión en el segundo nivel de especificidad más allá de las veinticinco letras del alfabeto, a no ser que se acuda al recurso de duplicar letras. Pero si bien es cierto que las mayúsculas aparecen duplicadas con frecuencia, esto no se debe a la introducción de un concepto más específico, sino que es un recurso para mostrar la presencia de conceptos antónimos próximos.

El control del vocabulario y la elección de la terminología incluida en el seno del lenguaje documental lo lleva a cabo en la actualidad el equipo que gestiona Iconclass. Éste toma también en consideración las propuestas que le hacen llegar usuarios y estudiosos, que le remiten sus opiniones y posibles nuevas notaciones (candidatas) a través de Internet o por otros medios más tradicionales. Estas circunstancias propician que su desarrollo y evolución sea relativamente rápido. Pero además es un sistema abierto a las necesidades concretas de los usuarios, sin desvirtuar por ello su naturaleza o menoscabar el control terminológico, puesto que en la versión que aparece en la WWW se les invita a que construyan nuevas notaciones siguiendo unas normas claras y definidas.

Con respecto a la localización física del documento, la notación resultante permite al usuario localizar la imagen en cuestión, ya sea en una estantería o una base de datos, en cuyo caso será la máquina la que coloque en un espacio digital dicha información, y, posteriormente, la extraiga cuando se le solicite.

Iconclass es un lenguaje diseñado para la indización y clasificación del Arte occidental; se significa como un lenguaje especializado, dado que no pretende abarcar todas las áreas de conocimiento en general. Sin embargo, Iconclass constituye el lenguaje documental sobre Arte más grande existente almacenado en una base de datos para indizar y clasificar materiales artísticos; y ofrece códigos o notaciones para casi todas las materias de Arte que pueden ser descritas. Aunque no ha sido vertido todavía a tantos idiomas como la CDD y la CDU, está ampliando el espectro lingüístico en el que hasta el momento está disponible: holandés, inglés, alemán, francés e italiano, y parece que está preparándose una versión en español. En cualquier caso, es la mejor herramienta documental para el tratamiento de contenido y búsquedas multilingües en Iconografía. La codificación

Scire. $10: 1$ (en.-jun. 2004) 51-64. 
alfanumérica independiente del lenguaje natural, tal y como ocurre en la CDD y la CDU, determina que no se vean afectadas las traducciones de las definiciones o "rúbricas" que acompañan a los códigos y que no altere su posición dentro de la estructura jerárquica. Desde esta perspectiva, su lenguaje "simbólico" puede considerarse un lenguaje "universal".

La indización/clasificación que se genera con este lenguaje documental es precoordinada (Izquierdo y Moreno, 1995), puesto que la notación generada en la descripción del documento icónico es fruto de haber combinado o coordinado los distintos elementos de acuerdo con el orden de citación prescrito por el propio sistema de clasificación. Por otro lado, las rúbricas son muchísimas veces auténticas definiciones, o constituyen expresiones muy complejas, que superan con creces lo que en la jerga de los lenguajes documentales se conoce como expresiones o términos precoordinados o incluso como términos compuestos. No son auténticos descriptores en sentido estricto, aunque haya ocasiones en que sus usuarios del mundo del Arte les llamen "descriptores", confundiéndolos con los términos simples o compuestos que integran el tesauro. El documento descrito por medio de Iconclass queda representado de una manera "sintética", es decir, la notación resultante o la proporción de códigos asignados para caracterizar el documento es menor que la que emplearíamos si nos hubiésemos servido de un lenguaje documental postcoordinado, como el tesauro. En tal caso, el número de descriptores manejado para caracterizar el documento, superaría la proporción de notaciones requeridas para clasificarlo. Eso no significa que la representación del documento sea necesariamente menos exhaustiva o amplia, ya que este factor no depende en sí mismo del número de términos o códigos barajados.

\section{Estructura de Iconclass}

La estructura de los lenguajes documentales comprende, en esencia, los elementos que se sintetizan en la tabla II. Una red semántica, compuesta por los términos o códigos que se emplean (o no) para indizar los documentos, los distintos tipos de relaciones que se establecen entre ellos y el sistema de referencias adoptado para especificarlas.

En los volúmenes que integran su estructura sistemática, Iconclass carece de "términos" aptos para clasificar y términos no aptos, igual que sucede con la CDU; pero en el índice alfabético sí figuran ambos. Aunque no abundan los términos equivalentes no preferentes, cuando aparecen, se advierte de su presencia mediante el reenvío de exclusión see (véase). A grandes rasgos, advertimos que las relaciones semánticas entre los términos son también muy ricas; lo que ocurre es que, como veremos poco más adelante, el sistema de referencias utilizado para indicarlas es muy pobre. Es mucho menos variado que en el tesauro y adopta más la forma de los reenvíos que utilizaban las listas de encabezamientos de materia

Scire. $10: 1$ (en.-jun. 2004) 51-64. 
see also (véase además). Por lo tanto, no se expone de modo expreso la diferencia entre las relaciones de jerarquía y asociación. Estos elementos contribuyen escasamente a controlar la ambigüedad del lenguaje. Ese cometido compete sustancialmente a la propia estructura del lenguaje documental clasificatorio, como sucede en la CDD o en la CDU, fundada en las reglas de la división lógica. La sucesiva subdivisión de las rúbricas impide en principio la repetición del concepto anterior; y la misma codificación artificial e independiente del lenguaje natural soslaya la sinonimia.

\begin{tabular}{|c|c|c|c|c|}
\hline & \multirow{3}{*}{ 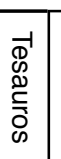 } & \multirow{3}{*}{ 읃 } & \multirow{3}{*}{ 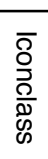 } \\
\hline & & & & \\
\hline \multicolumn{2}{|c|}{ ESTRUCTURA DE LOS LENGUAJES DOCUMENTALES } & & & \\
\hline $\begin{array}{l}\text { Red } \\
\text { semántica }\end{array}$ & $\begin{array}{l}\text { Descriptores (= Términos preferidos) } \\
\text { No descriptores } \\
\text { Microtesauros (= Clases) }\end{array}$ & $\begin{array}{l}+ \\
+ \\
+\end{array}$ & $\begin{array}{l}+ \\
- \\
+\end{array}$ & $\begin{array}{l}+ \\
+ \\
+\end{array}$ \\
\hline $\begin{array}{l}\text { Relaciones } \\
\text { semánticas } \\
\text { entre las } \\
\text { unidades } \\
\text { léxicas }\end{array}$ & $\begin{array}{l}\text { Relaciones de inclusión (\#pertenencia) entre términos y } \\
\text { microtesauros o clases } \\
\text { Relaciones de equivalencia semántica intralingüística: } \\
\text { entre un descriptor y un no descriptor o viceversa } \\
\text { Relaciones de equivalencia semántica interlingüística } \\
\text { entre descriptores de lenguas distintas } \\
\text { Jerarquía entre términos (TG, TE) } \\
\text { Asociación entre términos }\end{array}$ & $\begin{array}{l}+ \\
+ \\
+ \\
+ \\
+\end{array}$ & $\begin{array}{l}+ \\
- \\
+ \\
+ \\
-\end{array}$ & $\begin{array}{l}+ \\
+ \\
+ \\
+ \\
+\end{array}$ \\
\hline \multicolumn{2}{|c|}{ Estructura sindética compleja } & + & - & + \\
\hline $\begin{array}{l}\text { Control de la } \\
\text { ambigüedad }\end{array}$ & $\begin{array}{l}\text { División lógica y codificación numérica } \\
\text { Relaciones de equivalencia semántica intralingüística y } \\
\text { red semántica en su conjunto }\end{array}$ & - & $\begin{array}{l}+ \\
-\end{array}$ & $\begin{array}{l}+ \\
+\end{array}$ \\
\hline
\end{tabular}

Tabla II. Elementos constituyentes de Iconclass

Pero veamos con más detenimiento cómo se integran todos estos elementos en el cuerpo del lenguaje documental y cuál es su comportamiento. Los elementos que integran los diecisiete volúmenes de Iconclass publicados entre 1974 y 1985 son los cuatro que se analizan a continuación.

\subsection{Classification System (Sistema de Clasificación)}

Sistematiza el conocimiento del mundo del Arte en diez grandes clases, representadas por los dígitos comprendidos entre el 0 y el 9. De estas diez divisiones principales, los números que van desde el 1 hasta el 5 comprenden tópicos generales. Desde la 6 hasta la 9, aparecen temas más específicos, de naturaleza narrativa, como son la Historia $-6-$, la Biblia $-7-$, la Literatura $-8-$ y la Mitología Clásica e Historia Antigua -9-. Una división decimal, el número 0, 
fue añadida en 1996 a petición de los usuarios de Iconclass. Este número se destinó al arte abstracto o no figurativo. Este cuadro clasificatorio, salvo en la naturaleza de las materias recogidas, sigue las pautas marcadas por la CDD y la CDU. Cuando se quiere incrementar el nivel de especificidad, se procede a subdividir cada una de estas categorías, añadiéndosele un decimal. Pero a diferencia de las clasificaciones anteriores, el índice admite en el segundo nivel de la subdivisión letras mayúsculas, que posteriormente pueden seguir subdividiéndose:

División principal:

2 NATURE (NATURALEZA)

Subdivisión primaria:

21 the four elements; and ether, the 'fifth' element (los cuatro elementos; $y$ el éter, el quinto elemento)

\section{Subdivisión secundaria:}

21 D water (agua)

\section{Subdivisión terciaria:}

21 D 2 ice (hielo)

A partir de aquí es posible seguir agregando decimales para introducir conceptos más específicos. Los creadores de esta clasificación justifican la introducción de mayúsculas en las notaciones con tres argumentos: permite más número de subdivisiones en un determinado nivel; reduce las posibilidades de romper la coherencia del material descrito; y facilita la legibilidad de las notaciones. Un espacio en blanco separa las letras mayúsculas de las parejas de números y éstas entre sí, por ejemplo: 31 A 2351 sitting on the earth. Sin embargo, en lo entornos informáticos no se respeta esta pauta, poniéndose juntos todos los dígitos. En el desarrollo de un índice resulta frecuente que veamos en el segundo nivel de las subdivisiones letras mayúsculas duplicadas. Cuando eso ocurra, no debemos pensar que estamos ante una nueva subdivisión, introducida por una letra repetida en lugar del número decimal que le seguiría normalmente cuando se quiere desarrollar el concepto más genérico en otro de mayor especificidad. La duplicidad o desdoblamiento de la letra (doubling of letters) es sensible al contexto y sólo se utiliza en determinadas partes del sistema para mostrar el vínculo existente entre conceptos antónimos o conceptos cuya relación quiere mostrarse de manera expresa, dado que se encuentran semánticamente próximos, por ejemplo:

$11 \mathrm{H}$ and $11 \mathrm{HH}$ saints

$11 \mathrm{H}(\ldots)$ male saints for differentiation add NAME between brackets, and use the following STRUCTURAL DIGITS

$11 \mathrm{HH}(\ldots)$ female saints for differentiation add NAME between brackets, and use the following STRUCTURAL DIGITS

Scire. $10: 1$ (en.-jun. 2004) 51-64. 
Hay veces que al final de las rúbricas se localiza un reenvío o referencia cruzada hacia otro índice o índices que se juzgan relacionados con aquél desde el que se remite y viceversa. Su función es la de sugerir posibles opciones para clasificar un tema o para profundizar en la descripción del mismo. En la CDU ocurre lo mismo, pero se indica por medio de una flecha orientada hacia la derecha $\rightarrow$, mientras que en Iconclass la operación se efectúa invirtiendo el orden en el que aparecen el símbolo alfanumérico y la rúbrica, pues en los reenvíos aparece la rúbrica introducida por un sangrado y a ella le sigue su código, por ejemplo:

22 C 8 shadow

man and his shadow 31 A 28

Uno de los símbolos que aparecen casi constantemente a la derecha de las rúbricas es el "círculo suma" $\oplus$, que indica la existencia de referencias bibliográficas acerca de esa entrada. Por lo tanto, 22 C 8 shadow $\oplus$ indica que en la bibliografía sistemática, en esa misma notación, encontraremos las referencias bibliográficas que versan sobre esa clase.

\subsection{Bibliografía sistemática}

Efectivamente, una de las novedades que presenta Iconclass respecto de otros sistemas clasificatorios consiste en que, además del sistema de clasificación propiamente dicho, sus tablas sistemáticas presentan no sólo los índices con sus correspondientes enunciados y definiciones, sino que debajo de ellas muestran listada una vasta bibliografía que trata de este asunto. La edición en soporte papel muestra unas cuarenta mil referencias a libros y artículos de interés iconográfico y cultural. Así, por ejemplo, en las tablas sistemáticas podemos localizar, después de haber buscado el concepto deseado en el índice alfabético: 31 A 41 disabilities, deformations. Y si quisiéramos consultar las referencias existentes sobre estos conceptos, buscaríamos en la bibliografía, ordenada sistemáticamente de acuerdo con el sistema clasificatorio, y encontraríamos:

31 A 41 disabilities, deformations

Horapollo II 83 (a man born deformed but later taking on a normal shape, represented by a she-bear with cubs) - Motif-index of folk-lit. V: X100-X199 s.v. humor of physical disability. [...]

\subsection{Alphabetical index (Índice Alfabético)}

Hay en la edición impresa unas catorce mil entradas para localizar la notación necesaria para clasificar los documento y la correlación textual para describir o indizar esa imagen en cuestión. El índice alfabético constituye una herramienta muy valiosa para muchos iconógrafos durante el proceso de identificación, búsqueda y recuperación de información acerca de temas y escenas. No es un índice relativo inverso, como el que puede hallarse en la CDD o, en versión simplificada 
y empobrecida, en las ediciones anteriores a la del año 2000 de la CDU. Este índice presenta listadas alfabéticamente las rúbricas adjuntas a los códigos alfanuméricos por el vocablo que las encabeza, y, a continuación se listan en orden numérico creciente las expresiones que encabeza dicho término, como se observa en el siguente ejemplo:

covering

St. Francis of Assisi rejects his earthly heritage; standing before the bishop he gives his fine clothes to his father; the bishop covers Francis with his cloak $11 \mathrm{H}$ (FRANCIS) 33

covering the head, drawing drapery over the face 31 A 25313

roof-covering 41 A 362

El término que constituye la entrada o cabecera presenta una tipografía en negrita, que es además cursiva si el vocablo no figura en lengua inglesa. Los términos incorporan un calificador o modificador entre paréntesis cuando se hace necesario eliminar la la ambigüedad inherente a los vocablos homónimos.

El índice incorpora en cursiva reenvíos de orientación (see also), por medio de los cuales remite a expresiones relacionadas, evitando la dispersión que el orden alfabético impone en temas o materias susceptibles de relacionarse entre sí, y que, por lo mismo, pueden interesar al usuario para clasificar, indizar o recuperar información. Estas referencias desempeñan un papel análogo al que en los tesauros tiene el TR (término relacionado). Aunque no son muy abundantes, resulta asimismo factible encontrar términos sinónimos no preferentes, es decir, vocablos que no son aptos para clasificar o indizar los documentos. En este caso, los reenvíos de equivalencia o de exclusión nos advierten acerca de cuál es la expresión idónea para describir y clasificar el documento, con el tradicional 'véase' (see). Sin embargo, por lo menos en la edición en soporte papel, no encontraremos el reenvío inverso.

\subsection{Auxiliaries (Auxiliares o elementos sintácticos)}

Las notaciones básicas permiten la clasificación de una gran variedad de temas. Pero si queremos describir con detenimiento cualesquiera detalles iconográficos, requerimos de una importante flexibilidad notacional, que propociona en Iconclass un elaborado sistema de números auxiliares y otros elementos sintácticos, análogos a los que emplean otros lenguajes, como la CDU. Son cinco:

1. Special Key o Key Numbers (Claves Especiales o Números Clave): Los "números clave" tienen como misión facilitar una clasificación más detallada de la que pueden dar los índices básicos de Iconclass; es decir, introducen en la notación básica rasgos distintivos, características, aspectos o facetas, con la finalidadad de facilitar una mejor especificación del tema que se quiere describir.

Scire. $10: 1$ (en.-jun. 2004) 51-64. 
En este sentido, desempeñan igual cometido que los auxiliares especiales de la CDU, aunque en Iconclass hay menor variedad de ellos. Estos "números clave" - susceptibles a su vez de subdividirse - van precedidos del signo más o adición y se agregan a la notación encerrados entre paréntesis, al objeto de evitar que se confundan con los dígitos de las tablas. Figuran al final de cada volumen, y las propias tablas sistemáticas advierten por medio de un asterisco que precede a las rúbricas dónde y con qué números pueden utilizarse estas "claves". Por ejemplo, la notación para un león es $25 \mathrm{~F} 23$ (LION), siendo 25 F * animals; y el número subdividido introduce el concepto "león". El asterisco que precede al término "animals" nos advierte en el pie de página que pueden emplearse "números clave" en el 25 y sus subdivisiones. Por lo tanto, si queremos indicar además que se trata de una animal heráldico, escogemos el "número clave" +12 heraldic animals, con lo que la notación completa quedaría así: 25 F 23 (LION) (+12), que correspondería a león heráldico. Si quiere introducirse más de un concepto, es posible hacerlo añadiendo más números clave precedidos de la adición dentro del paréntesis. En este caso se ordenan de manera creciente. El índice alfabético también advierte de la posibilidad de recurrir a los "números clave" con determinados guarismos, e incluso proporciona ya confeccionadas diversas clasificaciones; por ejemplo:

Book-illumination

Painting, drawing, graphic arts see KEY (+35) to 48 [...]

book-illumination $48 \mathrm{C} 51(+35$ 3)

2. Combining of Notations (Combinación de Notaciones $u$ Otros elementos combinatorios): El elemento combinatorio por excelencia en este sistema de clasificación son los dos puntos o colon (:), cuya función es exactamente la misma que desempeña en la CDU. Sirven, por lo tanto, para coordinar o combinar dos notaciones con el fin de representar un tema complejo, si no queda bien descrito con una notación. Los códigos unidos por medio de los dos puntos se ordenan en virtud de la importancia que tiene cada uno en la descripción del tema; es decir, que aquellos dígitos que representan el tema principal, se colocan en primera posición, y, a continuación, se sitúan los demás. No hay ningún inconveniente, caso de que fuese preciso, en combinar más de dos notaciones. Por ejemplo, si quisiéramos describir que estamos ante una imagen en la que se nos muestra la resurrección de Lázaro saliendo de la tumba, escribiríamos 73 C 52 : 42 E 3. Esta notación está compuesta por:

73 C 52 Raising of Lazarus

42 E 3 grave, tomb

El propio índice alfabético muestra a veces las posibilidades de uso de los dos puntos en determinados contextos, ofreciendo combinaciones ya hechas que después se encuentran en las tablas sistemáticas.

Scire. $10: 1$ (en.-jun. 2004) 51-64. 
3. Bracket (paréntesis): En ciertos lugares de la estructura jerárquica, el usuario es invitado por medio de la frase with NAME a que añada un nombre, lo corrija, o a que introduzca un número o una combinación de todo lo anterior, con la finalidad de especificar mejor una notación, individualizándola o singularizándola entre otras más genéricas. Desempeña un cometido análogo a la especificación alfabética directa A/Z de la CDU. Por ejemplo, si en el índice buscamos

Aurochs

Hoofed animals (with NAME) 25 F 24 (...)

en las tablas sistemáticas vemos:

25 F 24 hoofed animals with NAME between brackets, e. g.: ANTELOPE, BISON

Otras veces el paréntesis con el nombre está ya incorporado en las tablas, por ejemplo: $11 \mathrm{H}$ (VICTOR) attributes of the martyr Victor of Marseilles. Millstone. El sistema clasificatorio en su conjunto es el que indica dónde y cómo se utiliza el paréntesis. Y en todo caso está indicado el lugar exacto en el que va ubicado el paréntesis, porque queda previsto cuándo los usuarios han de servirse de él. Así es que hay ocasiones en las que los nombres propios que figuran entre paréntesis vienen ya dados, mientras que en otras circunstancias sólo aparece el paréntesis con puntos suspensivos para que sea el investigador o documentalista el que escriba el nombre deseado. Pero los nombres siempre se redactan en letras mayúsculas.

4. Use of Zero (0) (Uso del cero 0): El 0 se emplea principalmente en esta clasificación para indicar representaciones alegóricas o simbólicas, aunque también se le localiza como un valor decimal, por ejemplo: 31 D 110 Infancy (alleg.)

5. Structural Digits (Dígitos estructurales): Originariamente, cuando se creó Iconclass, los dígitos estructurales eran directrices para estructurar la información relativa a grupos amplios de personalidades, como los dioses griegos, santos masculinos y femeninos, personajes de la historia clásica... Así, los episodios importantes en la vida de estos personajes fueron numerados consecutivamente con los llamados "dígitos estructurales". En la edición impresa, la aparición de estos dígitos en las tablas sistemáticas se advierte en nota a pie de página, pero el lector advierte su presencia en principio porque el primer vocablo que integra la rúbrica que acompaña al índice alfanumérico aparece en letra cursiva. Por ejemplo:

\section{$11 \mathrm{H}($ ADRIAN)}

$11 \mathrm{H}(\ldots) 1$ attributes of the warrior martyr Adrian(us) o Nicomedia... [...]

$11 \mathrm{H}($...) 6 martyrdom

A pie de página aparece esta nota: for STRUCTURAL DIGITS ( italiziced text) to $11 \mathrm{H}$ see p. 30

Scire. $10: 1$ (en.-jun. 2004) 51-64. 
Los dígitos estructurales forman parte de la notación y comparten con los números clave la propiedad de tener un significado intrínseco válido únicamente para una determinada parte de Iconclass, igual que los auxiliares especiales de la CDU varían su significado en virtud del contexto en el que aparecen. De hecho, salvo la propia advertencia del pie de página y de la letra cursiva, no existen reglas formales para establecer que un determinado número sea de hecho una estructura digital.

\section{Utilización de Iconclass}

Observando en la "Web" que cobija y difunde electrónicamente el inmenso trabajo de Van de Waal y sucesores las instituciones que emplean Iconclass para ordenar y describir sus colecciones de documentos icónicos por materias, estamos en condiciones de trazar el mapa donde se usa en la actualidad Iconclass. A la vista del mismo, percibimos que ha sido adoptado con largueza — máxime si se tienen en cuenta también los proyectos nacionales e internacionales-, pero en áreas geográficas muy concretas del "mundo occidental". De treinta entidades que se sirven de Iconclass, el $26 \%$ de ellas se encuentra en Inglaterra y el $23 \%$ en los Estados Unidos. Si incluimos a Canadá dentro de este grupo, veremos que nada menos que el $53 \%$ de los usuarios son países anglófonos. Los demás usuarios son países de la Europa occidental: Holanda, Alemania, Francia e Italia.

El peso específico de las instituciones que han apostado por Iconclass para ordenar y describir sus colecciones de imágenes en bases de datos es muy alto. En Estados Unidos, por ejemplo, figura la Fundación Getty; en Canadá, tenemos la Red para la Información sobre el Patrimonio Canadiense (Canadian Heritage Information Network, CHIN); en Francia, ha sido el Ministerio de Cultura la entidad que la escogió para su base de datos de arte. El International Committee for Documentation of the International Council of Museums (ICOM-CIDOC) recomienda Iconclass, entre otros diversos estándares o normas para la documentación de los objetos, etc. En España Iconclass ha pasado desapercibido hasta hace muy poco tiempo, con alguna excepción (García Marco y Agustín Lacruz, 1999). Ni en Arte, ni en Documentación ha merecido la atención de los profesionales. Pero con el proyecto APES, empiezan a cambiar las cosas. Se intenta elaborar una base de datos que recoja los diversos aspectos culturales de la imagen con fecha límite en 1800, para facilitar las investigaciones iconológicas. La clasificación y descripción de los documentos se efectúa con la edición disponible en línea Libertas, que podemos encontrar en la dirección http://www.iconclass.nl/libertas/ic. Ésta muestra las diez categorías en las que se divide la iconografía del mundo artístico. Cuando pulsamos sobre cada una de las carpetas que preceden a esas clases, descendemos por sus respectivas subdivisiones. Si nos interesa, escogemos las rúbricas que figuran a la derecha de los códigos alfanuméricos y buscamos en el 
índice alfabético (Keyword List) y entonces se nos muestran las ocurrencias de las expresiones que contienen los términos que configuran las rúbricas y los que les suceden alfabéticamente. Si escogemos uno de estos vocablos y pulsamos en él, se ven listados los códigos o notaciones que los contienen. Debajo y a la derecha de la pantalla se sitúa otra ventana denominada Keywords, que facilita el enlace de las divisiones y subdivisiones de Iconclass con los términos que sobre los temas a que apuntan contiene el Tesauro de Arte y Arquitectura del Instituto de Investigación Getty (Getty Research Institute). Aparte de la versión Libertas Iconclass suministra a quienes deseen adquirila la edición impresa, y, por supuesto, una edición digital.

\section{Conclusiones}

Iconclass es un lenguaje documental que permite indizar y ordenar sistemáticamente (clasificar) una colección de documentos icónicos relacionados con el Arte. Sin embargo, los códigos de Iconclass son algo más que una notación alfanumérica, dado que están concebidos para ir acompañados de su correspondiente rúbrica. Ésta proporciona un verdadero minirresumen temático en lenguaje controlado del documento en cuestión. Además, como proporciona descripción de las imágenes en contexto, facilita la datación de obras y la realización de estudios de inconografía evolutiva. A fin de que estas notaciones den mayores prestaciones durante la recuperación de la información, las bases de datos que hayan optado por Iconclass para el tratamiento de sus imágenes, deberían incluir un campo de descritores - de verdaderos descriptores - extraídos de las propias rúbricas. Fraccionadas éstas en términos simples o compuestos, permitirían elaborar índices por materias en lenguaje controlado con los que efectuar búsquedas temáticas. De este modo, un sistema de recuperación de la información que funcionase en lenguaje altamente controlado, tendría mayor facilidad para encontrar todos aquellos documentos cuyas rúbricas contuviesen esos términos. Un valor añadido es la opción de emplear la estructura clasificatoria del lenguaje para efectuar búsquedas jerárquicas o sistemáticas, seleccionando los conjuntos de documentos ordenados en virtud de la disposición arbórea del sistema.

La versión digital del sistema es la que ha facilitado su expansión, gracias a que las explicaciones sobre la utilización son muy asequibles para todas aquellas personas que no saben mucho acerca del funcionamiento de los lenguajes documentales. A su vez, esto ha derivado en una compatibilidad total con los sistemas operativos informáticos actuales. En España se acaba de comenzar a trabajar con este sistema de clasificación. El retraso respecto de otros países hay que buscarlo sin duda en la ausencia total de publicaciones en español sobre Iconclass y de traducciones que expliquen, siquiera sea de manera general, sus características y utilidades.

Scire. $10: 1$ (en.-jun. 2004) 51-64. 


\section{Referencias}

Waal, van de (1973-1985). Iconclass: an iconographic classification system. Amsterdam; Oxford; New York: North-Holland Publishing Company, 1973-1985. 17 vols.

García Marco, Francisco Javier; Agustín Lacruz, María del Carmen (1999). Lenguajes documentales para la descripción de la obra gráfica artística. En: Valle Gastaminza, Felix del (ed.). Manual de documentación fotográfica. Madrid: Síntesis, 1999. p. 169-204.

Iconclass (2003).URL:http://www.iconclass.nl/downloads/020815_IC_flyer2.pdf. Consultado: 2003-11-12

Izquierdo Arroyo, J. M.; Moreno Fernández, L. M. (1995). Problemas de terminología metalingüística en los lenguajes documentales de estructura combinatoria. // García Marco, F. J. (ed.). Organización del conocimiento en sistemas de información y documentación. 1. Zaragoza: ISKO, Universidad de Zaragoza, Vicerrectorado de Investigación; Madrid: Ministerio de Educación y Ciencia, 1995. 27-49 . 